\title{
SHAPING OF THE EVIDENCE-BASED SUBSTITUTION CONCEPTUAL FRAMEWORK OF THE ORIGINAL MEDICINES TO GENERIC COUNTERPARTS IN UKRAINE
}

\author{
Viktoriia Dobrova, Oleksii Popov, Igor Zupanets, Kateryna Tkachenko
}

\begin{abstract}
The aim. To develop conceptual framework of the strategy for a reasonable transition from original to generic medicines by complex implementation of proper bioequivalence studies and sufficient therapeutic drug monitoring management.

Materials and methods. To conduct the study, we used the lists of medicines included in the state reimbursement program "Dostupny Liky" (Affordable Medicines), and materials of reports on medicines public procurement provided on the website of the Ministry of Health of Ukraine and the National Health Service of Ukraine, as well as information data on the results of studies of the quality and effectiveness of these drugs provided by the Rx-Index website. In the course of the study, the methods of logical analysis, SWOT analysis, and statistical evaluation of results, Kingdon's Policy Streams Approach and the method of flowcharts construction were used. The concept of evidence-based medicine substitution formation in Ukraine was designed applying the Policy Streams Approach.

Results. The analysis of public procurement programs for drugs for the period 2018-2020, as well as the analysis of drugs included in the new list under the "Dostupny Liky" (Affordable Medicines) program, carried out in the course of the study, showed that the level of evidence of data on assessing their effectiveness remains low. At the same time, more than 1.5 billion UAH ( $50 \mathrm{mln}$ USD) is spent annually on the purchase of such drugs and reimbursement of their cost, and the question of the optimal selection and monitoring of pharmacotherapy with these drugs remains open. A structural model has been developed, in which three basic levels are identified: provision of regulatory and financial components, executive and the level of implementation of the results. The SWOT-analysis of the strengths and weaknesses, as well as external opportunities and threats for the implementation of the conceptual framework made it possible to substantiate the advantages and reveal the possibilities of attracting clinical centers of universities and research institutions to the implementation of the concept. A framework for the interaction of a research center with health care institutions in the implementation of therapeutic drug monitoring was developed for low-income and low-middle income countries on the example of Ukraine. Distribution of responsibilities was proposed and the basic principles of interaction between performers of therapeutic drug monitoring were highlighted.

Conclusions. Based on the results of the analysis of the evidence of the quality and effectiveness of drugs included in public procurement and in reimbursement programs, the key problems of organizing pharmaceutical provision of an appropriate level of quality for a number of chronic diseases requiring lifelong therapy were identified. The conceptual framework of evidence-based original medicines substitution to generic counterparts have been formed; and the ways of its implementation in the conditions of scarce financial resources on the example of Ukraine have been substantiated Keywords: bioequivalence, generic drug, therapeutic drug monitoring, narrow therapeutic index, evidence-based medicine, affordable medicines
\end{abstract}

\section{How to cite:}

Dobrova, V., Popov, O., Zupanets, I., Tkachenko, K. (2021). Shaping of the evidence-based substitution conceptual framework of the original medicines to generic counterparts in Ukraine. ScienceRise: Pharmaceutical Science, 4 (32), 67-77. doi: http://doi.org/10.15587/2519-4852.2021.239431

\section{Introduction}

The quality of patient treatment depends directly on the medicines used, their dosage, and the therapy regimen chosen. In case of proper combination of these factors, the effectiveness of medicines becomes maximum, whereas their possible harmful effects are minimized. The selection of effective pharmacological therapy for human diseases is a very complex task, and the key factor for its solving is proper pharmaceutical support, which includes original medicines, generic medicines (generics), and biosimilars (generic versions of original biotechnological medicines) [1]. This is especially true for medicines with a so-called narrow therapeutic index when the permissible deviation from the effective dose is very small $[2,3]$. Exceeding and reducing the dosage of such medicines is undesirable from the therapeutic, pharmacological and economic point of view, as well as for compliance ensuring [3, 4]. In addition, the problems of antibiotic resistance, treatment of patients with cardiovascular system diseases, bronchial asthma, diabetes mellitus, etc., whose pharmaceutical support is life-long, with full or partial funding from the state 
and/or local budgets, require the development of approaches to evidence-based, rational, and balanced use of medicines and generic substitutions for original drug products $[5,6]$.

A number of publications have been devoted to the issues of responsible attitude to research [7], registration $[6,8]$ and use of generics including economic benefits associated with substitute of original drugs to approved copy in USA, European Union some others countries [9] as well as Ukraine [10, 11]. Thus, a study of functioning of the Ukrainian state program "Affordable Medicines" has shown that mainly generic medicines are used for its pharmaceutical support [5]. Bioequivalence studies of these medicines as a key indicator of quality and conformity to the original drug $[7,11]$ remains an open question [10], which reduces confidence in these medicines in both, doctors and patients [5, 12]. Studies of such an important structural element of the National Health Policy as pharmaceutical care (PC) have proved the importance of creating conditions for the development of integrated interaction between the doctor, pharmacist, and patient to ensure proper, evidence-based, and informed pharmacotherapy (PT) [13].

Our review and analysis of science articles which were devoted to a different generic drugs policies in high income countries $[6,8]$, as well as low-middle income countries $[14,15]$, gave general study description and generic authority market rules $[7,11]$, substitution of original medicines to generic counterparts through implementation of international non-proprietary name prescribing $[8,16]$, price control for generics and interaction between stakeholders $[6,9]$. The small part of this research focused on the issue of generic substitution efficacy [6], and actually, none has paid sufficient attention to the need to formulate evidence-based rules for this process. Remarkably, that generic drug practices including prices and generic prescribing proportions widely vary across different countries and are not coherent [6]. The comprehensive overview made by Wouters et al. explores policy solutions to address issues in Europe and the United States, such as streamlining the generic drug approval process and requiring generic prescribing and substitution where such policies are not yet in place [6]. Cristofoletti. R. et al. describes the evolution of bioequivalence regulations up to the current day and discusses the potential of applying a Bayesian-like approach, considering all relevant prior knowledge, to guide regulatory bioequivalence decisions in a patient-centric environment [7].

A range of works is focused on the evaluation of generic drug policies basically or using a particular national case. Kalo et al. proposed the list of factors that influence the true efficiency of generic prescription drug policies in supporting public health initiatives in the developed world [8]. Other authors present the results of the evaluation of national generic drug policies performed using different approaches [7, 14]. Overall, these results reveal significant issues hampering effective generic drug policies that highlight the need for strengthening of the evidence base of the impact of generic drugs and further methodological research providing frameworks for building effective generic drug policies. Thus, to date, there is no widely accepted evidence-based framework for providing effective generic substitution. That is of great importance and requires further in-depth research.

At the same time, the issues of developing approaches to the evidence-based transition from original medicines to generics in routine medical practice remain open, as well as a systematic study of ways to improve the access of the population in Ukraine to proper PT with effective, safe, quality and affordable medicines.

The aim of the research. Given the above, the purpose of the study is to develop conceptual framework of the strategy for a reasonable transition from original to generic medicines by complex implementation of proper bioequivalence studies and sufficient therapeutic drug monitoring (TDM) management.

\section{Planning (methodology) of research}

The conceptual framework assuring evidencebased substitution of original drugs to generics is considered in this paper as a background for the agenda setting for future national generic drug policy. Therefore, it was reasonable to apply the methodological approaches enabling to understand the health policy as well as the context of its formulation. We decided to use Kingdon's Policy Streams Approach, which is one of the most prolific and widely recognized of the approaches in public policy making, especially in healthcare $[17,18]$.

According to Kingdon's Policy Streams Approach, the research methodology consisted of three domains $[19,20]$. The first was the problem stream that describes a problem or issue that needs to be resolved. Here we made analytical analysis and data assessment, which were used to determine the scope, relevance and economical significance of the problems related to evidence-based use medicines for patients with chronic diseases and permanent treatment as well as reasons and burdens of the present practice of generic drugs covering by reimbursement Ukrainian state program "Affordable Medicines".

The second domain tackles the policy stream that encompasses possible solutions or alternatives to this problem. Here we designed the evidence-based medicine substitution conceptual framework in Ukraine and drafting the policy brief for its implementation in the Ukrainian health care system.

The third domain described the politics stream covering political context that may or may not be favourable to the policy. To examine this, we applied SWOT analysis of the implementation of evidence-based use of medicine conceptual framework in Ukraine has been conducted.

Finally, the findings obtained through these three domains were used to develop recommendations and the framework for the management of conducting pharmacokinetic studies within TDM.

\section{Materials and methods}

Analysis was carried out based on the collected information from the lists and reports of public procurement of the Ministry of Health of Ukraine (MOH) [21], data and reports about functioning of "Dostupny Liky" (Affordable Medicines) program from the National Health Service of Ukraine (NHSU) [22, 23], and 
dashboard's NHSU information about dispensed drugs according to this reimbursement program [24]. For assessment of transparency and availability of the information about quality of drugs procured for the state budget costs the list of medicines which were included in "Dostupny Liky" (Affordable Medicines) program approved by $\mathrm{MOH}$ [23] and the open data from Rx-Index web-site were used [25]. All amounts in hryvnia (UAH) were converted into USD at the official exchange rate of the National Bank of Ukraine on July 26, 2021 (1 USD=27.048 UAH) [26].

The process of the conceptual framework of evidence-based medicine substitution formation in Ukraine was studied based on the Policy Streams Approach [19, 20]. The SWOT analysis was applied for identification of a strengths and weaknesses of conceptual framework implementation of evidence-based medicine substitution in Ukraine. The work also used methods for constructing structural and logical relationships, modelling processes and constructing flowcharts. Descriptive statistics methods such as calculation of a percentage (\%) and an average units were exploited on the different stage of analysis.

\section{Result}

Problem stream. Medical provision of PT in patients who need organ transplantation or other anatomical materials and are receiving immunosuppressive therapy requires significant funds, some of which are allocated from the state budget of Ukraine. Thus, in 2018-2020, $337.21 \mathrm{mln}$ UAH ( 12.49 mln USD) were spent for public procurement of medicines for transplantation (Table 1) and near 14.6 mln DDDs of such drugs as tacrolimus, everolimus, cyclosporine, etc. were purchased [21]. PT with these medicines requires proper selection, monitoring, and dose adjustment, as well as confidence that these expensive medicines purchased at both public and private expense are of the appropriate quality. Any inconsistencies in the treatment effectiveness and safety in these patients will lead to adverse reactions and even an increased risk of the transplanted organ rejection, which will require additional funds and increase the cost of PT $[2,3]$.

Another area for which 1.1 billion UAH ( 41.7 mln USD) was spent from the state budget in 2018-2020 is the purchase of medicines for tuberculosis treatment (Table 1) [21]. The volume of purchases amounted to more than $93 \mathrm{mln}$ DDDs, among which systemic antibacterial drugs (levofloxacin, moxifloxacin, amikacin, isoniazid, rifampicin, protionamide, etc.) predominate. The unverified effectiveness (equivalence) of these INN generic medicines leads to a potential decrease in their antimicrobial activity and, as a result, the formation of persistent antibiotic resistance in some population groups of Ukraine. This problem will require additional funds, including state funds, for the purchase of more expensive medicines [27].

Thus, in 2018-2020 the purchase of medicines for treatment of deceases which needs a monitoring of PT and control of switching from original medicine to generics was constant near 50-57 mln USD (1.3-1.5 billion UAH) during 2018-2019 and raised up to $99.67 \mathrm{mln}$ USD (2.7 billion UAH) in 2020.

Table 1

Data on the volume of public procurement of medicines requiring proper dosage selection in 2018-2020

\begin{tabular}{|c|c|c|c|c|c|c|}
\hline \multirow{2}{*}{$\begin{array}{l}\text { Area of public } \\
\text { procurement of } \\
\text { medicines }\end{array}$} & \multicolumn{2}{|c|}{2018} & \multicolumn{2}{|c|}{2019} & \multicolumn{2}{|c|}{2020} \\
\hline & $\begin{array}{l}\text { Ordered, } \\
\text { units }\end{array}$ & $\begin{array}{l}\text { Funds allocat- } \\
\text { ed for the } \\
\text { current budget } \\
\text { year, mln } \\
\text { USD }\end{array}$ & $\begin{array}{l}\text { Ordered, } \\
\text { units }\end{array}$ & $\begin{array}{l}\text { Funds allo- } \\
\text { cated for the } \\
\text { current } \\
\text { budget year, } \\
\text { mln USD }\end{array}$ & $\begin{array}{l}\text { Ordered, } \\
\text { units }\end{array}$ & $\begin{array}{l}\text { Funds allocat- } \\
\text { ed for the cur- } \\
\text { rent budget } \\
\text { year, mln USD }\end{array}$ \\
\hline Transplantation & 3746354 & 3.3 & 4351588 & 3.94 & 6451607 & 5.25 \\
\hline $\begin{array}{l}\text { Tuberculosis } \\
\text { (medicines) }\end{array}$ & 25231250 & 16.5 & 27965666 & 8.7 & 40269182 & 15.5 \\
\hline $\begin{array}{c}\text { Diabetes mellitus } \\
\text { (insulins, test } \\
\text { strips) }\end{array}$ & 6646564 & 0.73 & 8812632 & 0.73 & 15881588 & 1.12 \\
\hline $\begin{array}{l}\text { Affordable Medi- } \\
\text { cines program }\end{array}$ & $\begin{array}{c}144500000 \\
0 *\end{array}$ & 37.04 & $680953161 *$ & 37.04 & $\begin{array}{c}440872262 \\
*\end{array}$ & 77.8 \\
\hline Total amount & $1.5 \mathrm{bln}$ & 57.57 & 717731459 & 50.41 & 481141444 & 99.67 \\
\hline
\end{tabular}

Note: * the volume of pharmacy sales of medicines included in the Affordable

Medicines program, in physical terms (DDD, units), the cost of which is reimbursed [22, 24].

PT of patient groups with chronic cardiovascular diseases (CVD) and diabetes mellitus (DM), type I and II, are also partially provided through the "Dostupny Liky" (Affordable Medicines) program and certain areas of public procurement. The reimbursement amount for medicines in these areas increases annually, both, in nomenclature and physical terms, as well as in monetary terms (Tab. 1). Since 2021, it has been planned to reimburse the cost of medicines for patients with epilepsy, mental and behavioural disorders [23]. At the same time, our analysis of drug equivalence/originality for the treatment of CVD and type II DM included in the list of reimbursed medicines according to "Dostupny Liky" (Affordable Medicines) program approved by $\mathrm{MOH}$ [23] shows that this information is open and available to the doctors, pharmacists, and patients only for $23 \%$ of medicines (Table 2).

There are three antidiabetic INNs in the program Metformin, Glibenclamide and Gliclazide. The largest number of trade names (TNs) in the program is represented by metformin -37 , for which information about efficacy, safety and quality is available for only 5 
(13.5\%). Moreover, Gliclazide has the highest percentage of TN with available equivalence/ originality data -
$75 \%-6$ of 8 TNs included in the reimbursement for type II DM therapy (Table 2).

Table 2

Analysis of the verified drug equivalence/originality for the treatment of CVD and type II DM in the new register of the "Dostupny Liky" (Affordable Medicines) reimbursement program

\begin{tabular}{|c|c|c|c|c|}
\hline ATC-code & $\begin{array}{c}\text { International } \\
\text { non-proprietary name }\end{array}$ & $\begin{array}{c}\text { Quantity of } \\
\text { trade } \\
\text { names }\end{array}$ & $\begin{array}{l}\text { Type of bioequivalence studies } \\
\text { conducted for the drug }\end{array}$ & $\begin{array}{l}\text { Quantity of drugs in Rx- } \\
\text { Index [25] for which } \\
\text { information on equiva- } \\
\text { lence/ originality is } \\
\text { available, } \mathrm{n}(\%)\end{array}$ \\
\hline A10BA02 & Metformin & 37 & Trials in vivo - BE (B.1) & $5(13,5)$ \\
\hline A10BB01 & Glibenclamide & 3 & Comparative CT (B.4) & $2(67)$ \\
\hline \multirow{3}{*}{ A10BB09 } & \multirow{3}{*}{ Gliclazide } & \multirow{3}{*}{8} & Comparative CT (B.4) & $2(25)$ \\
\hline & & & Trials in vivo - BE (B.1) & $2(25)$ \\
\hline & & & Original drugs $(A)$ & $2(25)$ \\
\hline B01AA03 & Warfarin & 10 & - & $0(0)$ \\
\hline B01AC04 & Clopidogrel & 22 & Comparative CT (B.4) & $6(27)$ \\
\hline C01AA05 & Digoxin & 2 & Comparative CT (B.4) & $2(100)$ \\
\hline C01BD01 & Amiodarone & 9 & Comparative CT (B.4) & $4(44)$ \\
\hline C03AA03 & Hydrochlorothiazide & 9 & Comparative CT (B.4) & $1(11)$ \\
\hline C03CA01 & Furosemide & 4 & Comparative CT (B.4) & $3(75)$ \\
\hline C03DA01 & Spironolactone & 5 & - & $0(0)$ \\
\hline C07AB02 & Metoprolol & 8 & Comparative CT (B.4) & $2(25)$ \\
\hline C07AB03 & Atenolol & 4 & Comparative CT (B.4) & $1(25)$ \\
\hline C07AB07 & Bisoprolol & 29 & $\begin{array}{c}\text { Trials in vivo - BE with origi- } \\
\text { nal drug (B.1.1) }\end{array}$ & $4(13.8 \%)$ \\
\hline C07AG02 & Carvedilol & 15 & - & $0(0)$ \\
\hline \multirow{2}{*}{ C08CA01 } & \multirow{2}{*}{ Amlodipine } & \multirow{2}{*}{36} & Comparative CT (B.4) & $4(11)$ \\
\hline & & & Trials in vivo - BE (B.1) & $6(17)$ \\
\hline C08CA05 & Nifedipine & 4 & Comparative CT (B.4) & $1(25)$ \\
\hline C08DA01 & Verapamil & 4 & Comparative CT (B.4) & $2(50)$ \\
\hline C09AA02 & Enalapril & 20 & Comparative CT (B.4) & $6(30)$ \\
\hline C09CA01 & Losartan & 19 & - & $0(0)$ \\
\hline \multirow{2}{*}{ C10AA01 } & \multirow{2}{*}{ Simvastatin } & \multirow{2}{*}{15} & Comparative CT (B.4) & $3(20)$ \\
\hline & & & Trials in vivo - BE (B.1) & $2(13)$ \\
\hline
\end{tabular}

Note: $C T$ - clinical trials, $B E-$ bioequivalence

There are 17 INNs for treatment of CVD included in the program. For four of them - Warfarin, Spironolactone, Carvedilol and Losartan there is no open information about the conducted comparative studies for any of the presented TNs. Medicines for CVD treatment for which there is the greatest amount of information about their equivalence/originality are Digoxin and Furosemide (Table 2). For Digoxine both TNs included in the list presented information on their therapeutic equivalence. As for Furosemide 3 out of 4 TNs $(75 \%)$ provided information. For the remaining INNs, the percentage of TNs that showed therapeutic equivalence data is $50 \%$ or less.

For further analysis, we used data detailing dispensed drugs according to the Reimbursement Program "Affordable Medicines" for 2019 and 2020 years, presented on the dashboards of the National Health Service of Ukraine [24]. For understanding the amount of spending on medicines with proven and open data on effectiveness and quality, the amount of reimbursement for each TN included in the program by respective INN for the respective year was divided by the amount of reimbursement for medicines with known therapeutic equivalence (Table 3). Moreover, the total amount was calculated for all $\mathrm{TN}$ included in the program and the overall percent of medicines with proven data on effectiveness and quality based on publicly available data from RxIndex 2018 was estimated. This allowed us to understand the picture of how many of the actually dispensed drugs, the cost of which was reimbursed, were drugs with known equivalence data. For example, the program includes 11 TNs of Hydrochlorothiazide, of which 1 has available BE data. In 2019, only this medicine was prescribed and dispensed in pharmacies, respectively, the calculated value was $100 \%$. Whereas in 2020, 2 drugs were already reimbursed, one of which did not provide data and the value reduced. However, for most of the INNs values for 2019 and 2020 were consistent (Table 3). Total value percentage of funds spent on medicines with proven data on effectiveness and quality were $28 \%$ in 2019 and $27 \%$ in 2020. 
Analysis of reimbursement spending on medicines with proven data on effectiveness and quality based on publicly available data from Rx-Index 2018

\begin{tabular}{|c|c|c|c|c|c|c|}
\hline \multirow[t]{2}{*}{$\begin{array}{c}\text { International } \\
\text { non-proprietary name }\end{array}$} & \multicolumn{2}{|c|}{$\begin{array}{l}\text { The total amount of } \\
\text { reimbursement, USD }\end{array}$} & \multicolumn{2}{|c|}{$\begin{array}{c}\text { The amount of reimbursement } \\
\text { for therapeutic equivalent } \\
\text { medicines, USD }\end{array}$} & \multicolumn{2}{|c|}{$\begin{array}{l}\% \text { of funds spent on } \\
\text { medicines with } \\
\text { proven data on } \\
\text { effectiveness and } \\
\text { quality }\end{array}$} \\
\hline & 2019 & 2020 & 2019 & 2020 & 2019 & 2020 \\
\hline Metformin & 3862730 & 5955385 & 1639174 & 2495920 & 42.44 & 41.91 \\
\hline Glibenclamide & 31298 & 4466 & 20383 & 2783 & 65.13 & 62.32 \\
\hline Gliclazide & 1778424 & 2636693 & 1573031 & 2279597 & 88.45 & 86.46 \\
\hline Warfarin* & - & - & - & - & - & - \\
\hline Clopidogrel & 3835004 & 5238584 & 800728 & 980350 & 20.88 & 18.71 \\
\hline Digoxin & 40529 & 51501 & 40529 & 51501 & 100.00 & 100.00 \\
\hline Amiodarone & 572128 & 867076 & 412440 & 567157 & 72.09 & 65.41 \\
\hline Hydrochlorothiazide & 510885 & 715327 & 510885 & 669671 & 100.00 & 93.62 \\
\hline Furosemide & 32257 & 39258 & 11903 & 13774 & 36.90 & 35.09 \\
\hline Spironolactone & 1838956 & 2804095 & 0 & 0 & 0.00 & 0.00 \\
\hline Metoprolol & 73976 & 103278 & 3662 & 5982 & 4.95 & 5.79 \\
\hline Atenolol & 18330 & 28638 & 867 & 1537 & 4.73 & 5.37 \\
\hline Bisoprolol & 1301695 & 1568318 & 232691 & 286079 & 17.88 & 18.24 \\
\hline Carvedilol & 1046521 & 1466175 & 0 & 0 & 0.00 & 0.00 \\
\hline Amlodipine & 858873 & 1126648 & 188710 & 278008 & 21.97 & 24.68 \\
\hline Nifedipine* & - & - & - & - & - & - \\
\hline Verapamil & 33509 & 38820 & 9355 & 12022 & 27.92 & 30.97 \\
\hline Enalapril & 1000255 & 1429995 & 426454 & 708899 & 42.63 & 49.57 \\
\hline Losartan & 2704903 & 4262410 & 0 & 0 & 0.00 & 0.00 \\
\hline Simvastatin & 2638076 & 3303876 & 343776 & 278457 & 13.03 & 8.43 \\
\hline Total & 22178349 & 31640543 & 6214588 & 8631737 & 28.02 & 27.28 \\
\hline
\end{tabular}

Note: * These medicines have been included in reimbursement program "Dostupny Liky” (Affordable Medicines) since 2021

Taking into consideration the different reimbursement percentage for different trade names of medicines for the treatment of CVD and type II DM included in our analysis (Tab. 3), as well as the lack of official data on the originality/equivalence of these medicines [5, 11 ], it can be assumed that majority of budget funds under the "Affordable Medicines" program (approximately $70 \%$ ) are spent on medicines with unproven and/or unknown effectiveness and safety. It is important to note that local budgets also spend money to purchase these groups of medicines, so when forming technical requirements for the subject of the procurement it is advisable to have information about the quality of such medicines.

Thus, our analysis of government expenditures on drug purchases and assessment of the level of evidence as for the effectiveness and safety of medicines included in reimbursement programs shows that the issue of the quality of these medicines and the optimality of their indication, as well as compliance of standard PT regimens with individual needs of patients, remains open.

Policy stream. To solve the abovementioned problems, we have developed a conceptual framework of evidence-based use of medicines in Ukraine. The structural model of which is presented in Fig. 1. The purpose of this conceptual framework is to create conditions for the rational use of medicines requiring additional efforts for their appropriate dose selecting, monitoring, and therapy adjusting, as well as to reduce the unjustified burden on the state budget by reducing the potential costs of treatment complications caused by irrational use of medicines with unproven quality.

We suggest three basic levels of implementing the conceptual framework of evidence-based medicine substitution in Ukraine: ensuring its statutory, regulatory, and financial components. Performing bioequivalence (BE) and biosimilar studies, and conducting TDM, as well as implementing their results in the routine practice of the healthcare system (Fig. 1). Each of these levels requires the use of its methodological approaches to problem analysis, developing policies and strategies for implementing elements of the conceptual framework and concept developing, as well as control/audit indicators and improvement tools.

The development of a strategy for implementing the concept of evidence-based medicine substitution in Ukraine should take place at the level of ensuring statutory, regulatory, and financial components. At this stage, it is necessary to involve key stakeholders, being decisionmakers in the formation of the development of the national health policy, namely the Ministry of Health $(\mathrm{MOH})$ of Ukraine, State Enterprise State Expert Center of the Ministry of Health of Ukraine, the NHSU, and State Enterprise Public Procurement, as well as representatives of local self-government bodies that should be involved in the development and implementation of the concept at the local level. 


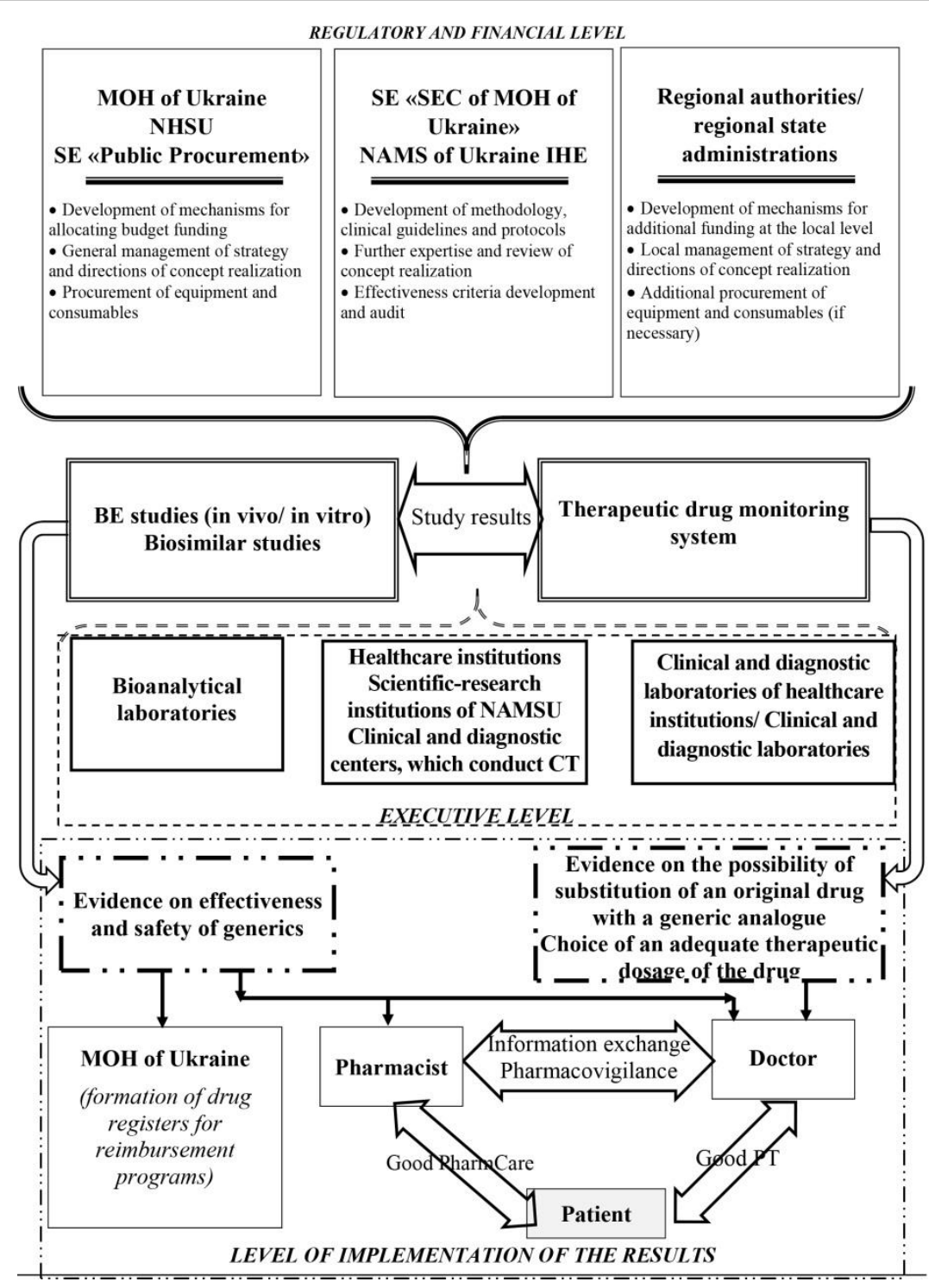

Fig. 1. Structural model of the evidence-based medicine substitution conceptual framework in Ukraine

For scientific expertise and development of the necessary recommendations, guidelines, and clinical protocols, it is necessary to invite leading scientists of the National Academy of Medical Sciences (NAMS) of Ukraine and Institutions of Higher Education (IHE) in the field of healthcare, in addition to experts of SE State Expert Center of the MOH of Ukraine (Fig. 1).

An important level of this conceptual framework implementation is the executive one, which should ensure the implementation of two basic tasks of this concept: the first is to improve the quality of generic medicines included in state programs of medical guarantees by increasing the number of BE/biosimilars studies in Ukraine and increasing the level of transparency as for their equivalence and safety (Fig. 1).

The second task is to create a domestic TDM system and incorporate it in the complex of ensuring the quality of patient treatment along with the system of Pharmacovigilance, proper Pharmaceutical Care (PC), and PT.

Effective functioning of the BE study system and increasing the number of these studies in Ukraine should be considered as an important tool for:
- ensuring proper selection of generics in the Register of medicines subject to reimbursement programs, and forming the nomenclature of medicines and requirements to them for public procurement,

- increased transparency of evidence for therapeutic equivalence and bioavailability of generic medicines,

- improving the level of rational use of medicines,

- increasing the investment attractiveness of the Ukrainian pharmaceutical market in the field of drug development and research.

In the pharmaceutical market of Ukraine, there are three clinical and diagnostic centers where the clinical part of BE studies takes place and three bio-analytical laboratories that perform bioanalytical studies of pharmacokinetics in biological samples [10]. All these research bodies are properly provided according to the international requirements for conducting such clinical trials (CT), have sufficient experience in their implementation, have participated in programs of both, domestic clinical audits and international inspections, and have a great potential to increase the number of BE studies performed, as well as to conduct pharmacokinetic studies within TDM. 
For TDM system implementation, the executive level primarily covers health care institutions that provide secondary and tertiary medical care to patients with the above-mentioned diseases, as well as clinical and diagnostic laboratories with an appropriate level of technical equipment, methodological, and professional support.

Usually, it can take about four or six weeks to select the dosage regimen of one of the medicines with a narrow therapeutic index, and in more complex cases, even up to 60 days. For the whole period, the patient should be hospitalized in secondary or even tertiary medical institutions, which significantly increases the cost of his/her treatment and requires additional costs under the program of medical guarantees, TDM allows reducing significantly the patient's time spent in the hospital (up to 12-15 days), and at the same time, reducing significantly the cost of the treatment. Implementation of TDM may allow dosage monitoring and optimization (e. g., anticonvulsants) in many patients, at the primary care level without hospitalization, In addition to reducing the cost of treatment in such patients; this approach will improve the quality and effectiveness of PT.

At the third, executive level of implementing the conceptual framework of evidence-based medicine substitution, it is important to create the conditions for obtaining complete information about the quality, effectiveness, and safety of both, original medicines and generics, for doctors, pharmacists, and patients. It is at the executive level the Ministry of Health of Ukraine should introduce the mechanisms for including only generic medicines with proven equivalence in public procurement programs. Together with the exchange of information between the doctor and the pharmacist, as well as the implementation of the PC process by the pharmacist [14], proper PT based on TDM and information on the quality of generic medicines is the third component of ensuring evidence for medicines' use and the quality of patient treatment.

Politics stream. To identify strengths and weaknesses of the existing structure of the healthcare system, that are important for solving issues of PT monitoring and adjusting, as well as external opportunities and threats to the implementation of the conceptual framework, a SWOT analysis of the implementation of evidence-based use of medicine concept in Ukraine has been conducted (Table 4).

It is important to note that BE studies and TDM have common research methods and the same clinical and diagnostic centers may be involved in their implementation, which can provide a full cycle of research. At the same time, the development and implementation of the TDM system in Ukraine provide an opportunity to attract highly specialized institutions of the National Academy of Medical Sciences of Ukraine to conduct pharmacokinetic studies for both, PT monitoring and BE studies in vivo, which is a potentially favourable factor for the development of the conceptual framework suggested (Table 4).

Table 4

SWOT analysis for the conceptual framework implementation of evidence-based medicine substitution in Ukraine

\begin{tabular}{|l|}
\hline \multicolumn{1}{|c|}{ Strengths (internal) } \\
\hline - In Ukraine. there are three KDCs and bioanalytical \\
laboratories capable of conducting pharmacokinetic \\
studies
\end{tabular}

- Health care institutions have clinical and analytical laboratories with fairly good equipment and infrastructure.

- Development of commercial clinical and analytical laboratories.

- Providing personnel support for the development of such a conceptual framework through the educational programs of Clinical Pharmacy, Clinical Studies, and Laboratory Diagnostics.

\begin{tabular}{|c|c|} 
Opportunities (external) \\
\hline - Potential reduction in adverse reactions/adverse
\end{tabular} events.

- Reducing the cost of therapy by preventing the occurrence of side effects, resistance, and dose titration.

- Potential possibility of attracting KDCs and bioanalytical laboratories, as well as highly specialized institutions of the National Academy of Medical Sciences of Ukraine, to conduct TDM and create evidencebased PT centers on their basis.

- Conducting a risk/benefit assessment of replacing the original medicine with a generic one at the beginning of therapy under the supervision of a clinical pharmacologist and/or clinical pharmacist.

- Insufficient number of bioanalytical laboratories.

- Time and resources are required to develop, verify, and validate new bioanalytical (chromatographic) methods for TDM.

- It is necessary to attract additional funding for the purchase of additional equipment.

- It is necessary to provide educational training and explain the importance of conceptual framework implementation as a whole and TDM as its component to the doctors.

- Absence of secondary and tertiary links of the structures involved in clinical pharmacology and TDM in health care institutions.

Threats (external)
- The initiation of the conceptual framework requires improvement of legislation in the field of healthcare.

- The implementation and development of the conceptual framework require additional funding.

- The risk of reducing funding for the conceptual framework development program is associated with limited medical budget items and possible emergencies.

- Changes in the state policy and priorities.

- Potential resistance of pharmaceutical companies to implement quality assessments of generic medicines when they are included in government procurement programs.

- Lack of economic assessment of the benefits/costs of eliminating the occurrence of adverse reactions in the treatment with generic medicines with unproven effectiveness and the selection of PT medicines with a narrow therapeutic index in the existing system of medical services. 
In the future, it is necessary to work out and develop principles, strategies and scenarios of interaction between key stakeholders to ensure the implementation of the conceptual framework, conduct research on potential risks and opportunities of domestic clinical and diagnostic laboratories and medical institutions when implementing it, as well as to form a strategy for implementing the concept, taking into account the SWOT analysis conducted.

The framework for pharmacokinetic studies within $T D M$. Considering this, we have formulated a general framework for involving the Clinical and Diagnostic Center of the National University of Pharmacy (CDC of $\mathrm{NUPh}$ ) in the introduction of TDM in the north-eastern region of Ukraine (Fig. 2). It is important to note that the CDC of NUPh is one of the three centers in Ukraine where studies BE are conducted, and it is certified by the World Health Organization for conducting pre-marketing drug studies. The advantages of the CDC of NUPh are determined by the possibility of patients' hospitalization in the Center for the period of monitoring, providing them with standardized nutrition and water, and by the experience of specialists in conducting clinical trials. The Laboratory of Clinical Diagnostics within the Center is equipped with modern medical and bioanalytical equipment, has appropriate accreditation, and ensures the proper level of quality of research. Thus, its use as a pilot Center for the implementation of the conceptual framework suggested and the establishment of option for interaction between the Ministry of Health of Ukraine as the central executive authority in the field of healthcare and local state administrations and local self-government bodies of the north-eastern region of Ukraine has economic, scientific and practical advantages. Following this example, 5-6 medical centers from different regions of Ukraine could be selected to implement the suggested concept; and on their base, the conceptual framework developed by us will be implemented.

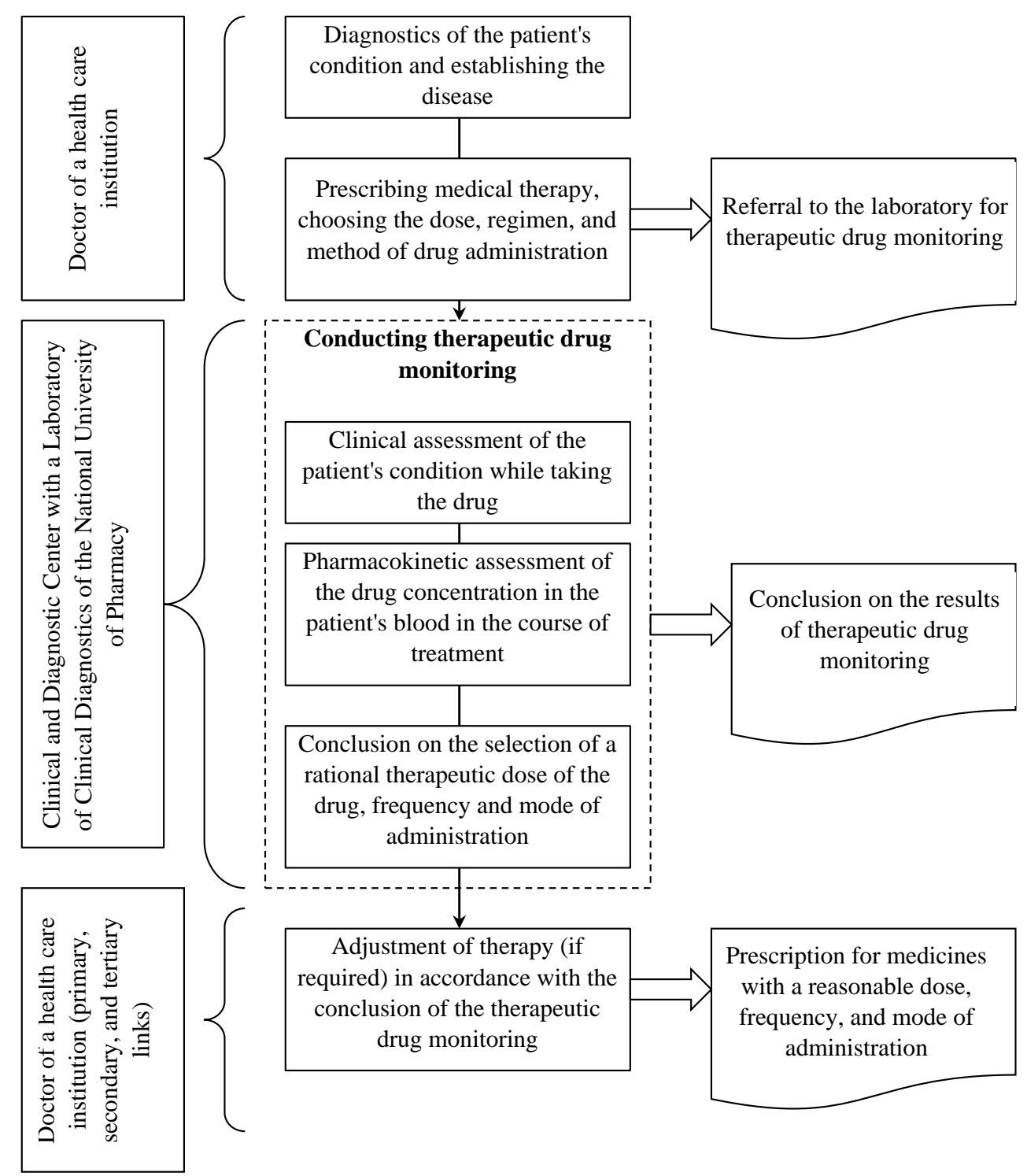

Fig. 2. Flowchart of the research center interaction with a health care institution during the implementation of TDM using north-eastern region of Ukraine as a case study

To ensure the effective promotion of the conceptual framework of evidence-based medicine substitution in Ukraine, in particular its part and tasks related to TDM, it is important to shape basic principles of interac- 
tion between key performers. In accordance with the components of TDM execution processes defined by the flowchart (Fig. 2) we have suggested distribution of responsibilities and identified the basic steps of interaction between performers, which include the following:

1) the Regional Healthcare Department in the Kharkiv region shall provide regulatory support for the project and organizes methodological and explanatory work among doctors;

2) the Laboratory of Clinical Diagnostics under the CDC of NUPh shall be the responsible executor for conducting analytical procedures in the implementation of TDM, it should be provided with all the necessary bioanalytical equipment and reagents; it should develop methods for TDM and their validation, develop standard operating procedures, and conduct the necessary studies for TDM;

3) healthcare institutions in the Kharkiv region at the level of secondary and tertiary medical care shall diagnose the patient's condition and assess the dynamics of the disease, and prescribe medicine, as well as refer the patients to the CDC of NUPh for TDM, and according to the results of the latter, adjust drug indication and dose.

Such interaction between the Regional Healthcare Department of the Kharkiv region and the Laboratory of Clinical Diagnostics under the CDC of NUPh could allow creating a consultation service for conducting TDM to the population and effective PT, which will include specialized doctors, clinical pharmacists, laboratory assistants, and scientists of the University. This meets the European requirements for ensuring the quality of TDM [2].

\section{Discussion}

In this context, it is important to note that, in contrast to these existing generic substitution policies in the world, our proposed conceptual framework is aimed at comprehensively solving the problem of evidence-based generic substitution of original drugs that require additional attention (drugs with a narrow therapeutic index, immuno-suppressive, etc.) by combining proper $\mathrm{BE}$ studies and TDM. This framework is the first step made in constructing theoretical evidence-based background for the national generic substitution therapy. It is based on the analysis of current problems, review of possible solution alternatives and relevant national context in which the generic substation practices are developing. The important point of this framework is the data-driving approach that implies the integration of data from $\mathrm{BE}$ and biosimilar studies as well as TDM. The second point is the clear structure of communications between stakeholders involved that is essential for consistent generic substitution practices implementation at different levels. In this way, the conceptual framework creates an essential basis for developing evidence-based generic drug policies.

One of the weaknesses of the conceptual framework suggested, as determined by the conducted SWOT analysis (Table 4), is a need to allocate additional funding, which is enhanced by the presence of an external threat of limited funding for the health system and the potential reduction of these funds. For effective implementation of the conceptual framework, it is important to determine the number of centers needed for launching pilot projects, as well as to evaluate the existing capabilities of clinical centers of universities and science research institutions of the country and to develop a strategy for their rational inclusion at the executive level. The general framework implementation of TDM as a part of the evidence-based substitution conceptual framework determines the main steps for proper management TDM and collaboration between parts of the process (Fig. 2) while most known guidelines cover the narrow professional tasks of laboratory testing [2], a clinical question formulation [3], the impact of the test result on patient treatment decision [27].

Main parts of designed conceptual framework and general framework for involving the clinical research centers in the TDM implementation are aimed to address the different targeting issues of quality and safety assessment, selection, procurement, distribution and use of generic medicines. In the same time this new complex approach which combine proper BE studies and TDM should increase confidence in generics and promoting their acceptance by physicians, pharmacists and patients. The indisputable advantages of implementing the conceptual framework of evidence-based medicine substitution and TDM use as one of its components is reduced number of non-response cases, side effects, and the total number of overdose manifestations or incomplete unstable clinical effect from drug use for the treatment of chronic diseases with a high risk of complications from inappropriate PT. The conceptual framework provided in this article can be useful for low- and middle-income countries to develop and improve national medicines policies in context evidence-based switching from originator drugs to generic equivalents.

Study limitations. The obtained results of our research encompasses the issues that need to be emphasized, possible solutions or alternatives to for implementation of the conceptual framework of evidence-based medicine substitution in Ukraine and TDM use as one of its component. The conceptual framework formation is the first phase of policy-making and reflects how policies are arrived at, how to manage the dissemination of the project and what stakeholders have to be involved.

Prospects for further research. In further research, it is planned to work out and develop principles and scenarios of interaction between key stakeholders to ensure the implementation of the conceptual framework, taking into account the SWOT analysis conducted, to conduct a study of potential risks and opportunities of domestic clinical and diagnostic laboratories and medical institutions when implementing it, and to develop methodological recommendations required for organization of TDM and improving the effectiveness of BE studies. Further, the shaped evidence-based medicine substitution conceptual framework and suggested flowchart for TDM implementation will be deep evaluated including additional cost effectiveness analysis of this strategy, risk assessment of its implementation in public health and survey of professionals and patients opinion.

\section{Conclusions}

1. Our analysis of public procurement programs for medicines over the past three years and the study of 
the list of medicines included in the "Affordable Medicines" program shows that the level of evidence for data on effectiveness and safety evaluation of these medicines remains low, and the issue of optimal selection and monitoring of PT with these medicines remains open as well. It was shown, that in 2019-2020 years the majority of budget funds (approximately $70 \%$ ) which were spent on reimbursement under the Affordable Medicines program for the treatment of CVD and type II DM coved medicines with unproven and/or unknown effectiveness and safety.

2. The evidence-based substitution conceptual framework of the original medicines to generic counterparts in Ukraine was shaped through describing the problem stream, the policy stream and the politics stream which confluence is essential for the intended policy formulation. Its structural model, which includes three basic levels: ensuring statutory, regulatory, and financial components, executive level, and the level of implementation of results, is developed. The goals and objectives of the conceptual framework implementation have been defined, a SWOT analysis of weaknesses and strengths, as well as external opportunities and threats for it implementation, has been carried out.

3. The advantages and possibilities of involving clinical centers of universities and research institutions in the implementation of the concept are substantiated, and the framework for the interaction of the research center with health care institutions in the implementation of TDM is developed using Ukraine as a case study. The distribution of responsibilities is suggested, and the basic steps of interaction between performers during TDM are highlighted.

\section{Conflict of interests}

There are no conflicts of interests regarding this study.

\section{Financing}

The study was performed without financial support.

\section{References}

1. Maxwell, S. R. (2016). Rational prescribing: the principles of drug selection. Clinical Medicine, 16 (5), 459-464. doi: http://doi.org/10.7861/clinmedicine.16-5-459

2. Hiemke, C., Bergemann, N., Clement, H., Conca, A., Deckert, J., Domschke, K. et. al. (2017). Consensus Guidelines for Therapeutic Drug Monitoring in Neuropsychopharmacology: Update 2017. Pharmacopsychiatry, 51 (01/02), 9-62. doi: http://doi.org/10.1055/s0043-116492

3. Van Gelder, T. (2011). European Society for Organ Transplantation Advisory Committee Recommendations on Generic Substitution of Immunosuppressive Drugs. Transplant International, 24 (12), 1135-1141. doi: http://doi.org/10.1111/j.1432-2277.2011.01378.x

4. Liu, Q., Smith, A. R., Park, J. M., Oguntimein, M., Dutcher, S., Bello, G. et. al. (2018). The adoption of generic immunosuppressant medications in kidney, liver, and heart transplantation among recipients in Colorado or nationally with Medicare part D. American Journal of Transplantation, 18 (7), 1764-1773. doi: http://doi.org/10.1111/ajt.14722

5. Evaluation of the Affordable Medicines Programme in Ukraine (2019). WHO Regional office for Europe. Available at: https://www.euro.who.int/en/countries/ukraine/publications/evaluation-of-the-affordable-medicines-programme-in-ukraine-2019

6. Wouters, O. J., Kanavos, P. G., McKee, M. (2017). Comparing Generic Drug Markets in Europe and the United States: Prices, Volumes, and Spending. The Milbank Quarterly, 95 (3), 554-601. doi: http://doi.org/10.1111/1468-0009.12279

7. Cristofoletti, R., Rowland, M., Lesko, L. J., Blume, H., Rostami-Hodjegan, A., Dressman, J. B. (2018). Past, Present, and Future of Bioequivalence: Improving Assessment and Extrapolation of Therapeutic Equivalence for Oral Drug Products. Journal of Pharmaceutical Sciences, 107 (10), 2519-2530. doi: http://doi.org/10.1016/j.xphs.2018.06.013

8. Kaló, Z., Holtorf, A.-P., Alfonso-Cristancho, R., Shen, J., Ágh, T., Inotai, A., Brixner, D. (2015). Need for Multicriteria Evaluation of Generic Drug Policies. Value in Health, 18 (2), 346-351. doi: http://doi.org/10.1016/j.jval.2014.12.012

9. Dunne, S., Shannon, B., Dunne, C., Cullen, W. (2013). A review of the differences and similarities between generic drugs and their originator counterparts, including economic benefits associated with usage of generic medicines, using Ireland as a case study. BMC Pharmacology and Toxicology, 14 (1). doi: http://doi.org/10.1186/2050-6511-14-1

10. Introducing New Strategy on Bioequivalence in Ukraine. (2018). SAFEMed. Available at: https://www.msh.org/sites/ default/files/safemed_bioequivalence_tech_report_final.pdf

11. Popov, O. S., Kravchenko, I. V., Dobrova, V. Y., Tkachenko, K. M. (2021). The analysis of approaches to conducting bioequivalence studies and the policy of "transparency" of their results in Ukraine, the United States and the European Union. Clinical Pharmacy, 25 (1), 32-40. doi: http://doi.org/10.24959/cphj.21.1548

12. Maly, J., Zimcikova, E., Babica, J., Kubena, A. A., Kostriba, J., Mala-Ladova, K. (2019). Representative sample survey on factors determining the Czech physicians' awareness of generic drugs and substitution. BMC Health Services Research, 19 (1). doi: http://doi.org/10.1186/s12913-019-4631-y

13. Zupanets, I. A., Dobrova, V. Y., Shilkina, O. O. (2018). Development of Theoretical Approaches to Pharmaceutical Care Improvement Considering the Modern Requirements of Health-Care System in Ukraine. Asian Journal of Pharmaceutical and Clinical Research, 11 (8), 356. doi: http://doi.org/10.22159/ajpcr.2018.v11i8.26009

14. Sweet, C. M. (2017). The Politics and Policies of Regulating Generics in Latin America: A Survey of Seventeen States. Journal of Health Politics, Policy and Law, 42 (3), 485-512. doi: http://doi.org/10.1215/03616878-3802953

15. Ferrario, A., Sautenkova, N., Bezverhni, Z., Seicas, R., Habicht, J., Kanavos, P., Safta, V. (2014). An in-depth analysis of pharmaceutical regulation in the Republic of Moldova. Journal of Pharmaceutical Policy and Practice, 7 (1). doi: http://doi.org/10.1186/2052-3211-7-4

16. Mansilla, C., Cárdenas, J., Kaplan, W. A., Wirtz, V. J., Kuhn-Barrientos, L., Ortíz de Zárate, M. et. al. (2019). Evaluation of the effects of a generic substitution policy implemented in Chile. BMJ Global Health, 2 (Suppl 3), e000922. doi: http://doi.org/10.1136/bmjgh2018-000922

17. Jones, M. D., Peterson, H. L., Pierce, J. J., Herweg, N., Bernal, A., Lamberta Raney, H., Zahariadis, N. (2015). A River Runs Through It: A Multiple Streams Meta-Review. Policy Studies Journal, 44 (1), 13-36. doi: http://doi.org/10.1111/psj.12115

18. Mhazo, A. T., Maponga, C. C. (2021). Agenda setting for essential medicines policy in sub-Saharan Africa: a retrospective policy analysis using Kingdon's multiple streams model. Health Research Policy and Systems, 19 (1). doi: http://doi.org/10.1186/s12961-02100724-y 
19. Rawat, P., Morris, J. C. (2016). Kingdon's streams model at thirty: Still relevant in the 21 st century? Politics and Policy, 44, 608-638. doi: http://doi.org/10.1111/polp.12168

20. Giese, K. K. (2020). Coronavirus Disease 2019's Shake-up of Telehealth Policy: Application of Kingdon's Multiple Streams Framework. The Journal for Nurse Practitioners, 16 (10), 768-770. doi: http://doi.org/10.1016/j.nurpra.2020.08.015

21. Zakupivli Likiv. Informatsiia za Rokamy. MOZ Ukrainy. Available at: https://moz.gov.ua/zakupivli-likiv

22. Prohrama «Dostupni Liky»: pidsumky 2020 r. (2021). Apteka, 4 (1275). Available at: https://www.apteka.ua/article/582105

23. Pro zatverdzhennia reiestru likarskykh zasobiv yaki pidliahaiut reimbursatsii stanom na 10 liutoho 2021 roku (2021). Nakaz MOZ Ukrainy No. 251. 15.02.2021. Available at: https://moz.gov.ua/article/ministry-mandates/nakaz-moz-ukraini-vid15022021--251-pro-zatverdzhennja-reestru-likarskih-zasobiv-jaki-pidljagajut-reimbursacii-stanom-na-10-ljutogo-2021-roku

24. Detalizatsiia vidpushchenykh likarskykh zasobiv za prohramoiu reimbursatsii «Dostupni liky». Natsionalna sluzhba zdorovia Ukrainy. Available at: https://nszu.gov.ua/e-data/dashboard/reimb-manufacturer-details

25. Rx index - dovidnyk ekvivalentnosti likarskykh zasobiv. Available at: https://rx.ua/

26. Official Exchange Rate. National Bank of Ukraine. Available at: https://bank.gov.ua/en/markets/exchangerates?date=2021-0726\&period=daily

27. Mabilat, C., Gros, M. F., Nicolau, D., Mouton, J. W., Textoris, J., Roberts, J. A. et. al. (2019). Diagnostic and medical needs for therapeutic drug monitoring of antibiotics. European Journal of Clinical Microbiology \& Infectious Diseases, 39 (5), $791-$ 797. doi: http://doi.org/10.1007/s10096-019-03769-8

Received date 11.05.2021

Accepted date 26.07.2021

Published date 31.08.2021

Viktoriia Dobrova*, Doctor of Pharmaceutical Sciences, Professor, Department of Clinical Pharmacology and Clinical Pharmacy, National University of Pharmacy, Pushkinska str., 53, Kharkiv, Ukraine, 61002

Oleksii Popov, PhD, Assistant, Department of Clinical Pharmacology and Clinical Pharmacy, National University of Pharmacy, Pushkinska str., 53, Kharkiv, Ukraine, 61002

Igor Zupanets, Doctor of Medical Sciences, Professor, Department of Clinical Pharmacology and Clinical Pharmacy, National University of Pharmacy, Pushkinska str., 53, Kharkiv, Ukraine, 61002

Kateryna Tkachenko, PhD, Assistant, Department of Clinical Pharmacology and Clinical Pharmacy, National University of Pharmacy, Pushkinska str., 53, Kharkiv, Ukraine, 61002

*Corresponding author: Viktoriia Dobrova, e-mail: vd311270@gmail.com 